\title{
Circulating levels of matrix metalloproteinase-9 (MMP-9), neutrophil gelatinase-associated lipocalin (NGAL) and their complex MMP-9/NGAL in breast cancer disease
}

\author{
Xeni Provatopoulou ${ }^{1}$, Antonia Gounaris*1, Eleni Kalogera, Flora Zagouri², \\ Ioannis Flessas ${ }^{2}$, Evgenios Goussetis ${ }^{3}$, Afroditi Nonni ${ }^{4}$, \\ Ioannis Papassotiriou ${ }^{5}$ and George Zografos ${ }^{2}$
}

Address: ${ }^{1}$ Research Center, Hellenic Anticancer Institute, Athens, Greece, ${ }^{2}$ Breast Unit, First Department of Propaedeutic Surgery, Hippokratio Hospital, University of Athens, Athens, Greece, ${ }^{3}$ Stem Cell Transplant Unit, "Aghia Sophia" Children's Hospital, Athens, Greece, 4 First Department of Pathology, School of Medicine, University of Athens, Athens, Greece and ${ }^{5}$ Department of Clinical Biochemistry, "Aghia Sophia" Children's Hospital, Athens, Greece

Email: Xeni Provatopoulou - xprovatopoulou@yahoo.gr; Antonia Gounaris* - antgouna@otenet.gr; Eleni Kalogera - kalogerael@yahoo.gr; Flora Zagouri - florazagouri@yahoo.co.uk; Ioannis Flessas - iflessas@yahoo.gr; Evgenios Goussetis - mmo@paidon-agiasofia.gr; Afroditi Nonni - afnonni@med.uoa.gr; Ioannis Papassotiriou - ipapassotiriou@gmail.com; George Zografos - gzografo@med.uoa.gr

* Corresponding author

Published: 4 November 2009

BMC Cancer 2009, 9:390 doi:10.1 I86/147/-2407-9-390
Received: 8 April 2009

Accepted: 4 November 2009

This article is available from: http://www.biomedcentral.com//47/-2407/9/390

(C) 2009 Provatopoulou et al; licensee BioMed Central Ltd.

This is an Open Access article distributed under the terms of the Creative Commons Attribution License (http://creativecommons.org/licenses/by/2.0), which permits unrestricted use, distribution, and reproduction in any medium, provided the original work is properly cited.

\begin{abstract}
Background: Recent evidence suggests that neutrophil gelatinase-associated lipocalin (NGAL) expression is induced in many types of human cancer, while detection of its complex with matrix metalloproteinase-9 (MMP-9) is correlated with cancer disease status. We aim to evaluate the serum expression of MMP-9, NGAL and their complex (MMP-9/NGAL) during the diagnostic work-up of women with breast abnormalities and investigate their correlation with disease severity.

Methods: The study included II 3 women with non-palpable breast lesions undergoing vacuumassisted breast biopsy for histological diagnosis, and 30 healthy women, which served as controls. Expression levels of MMP-9, NGAL and their complex MMP-9/NGAL were determined in peripheral blood samples with immunoenzymatic assays.

Results: Women with invasive ductal carcinoma exhibited significantly increased levels of MMP-9, NGAL and MMP-9/NGAL compared to healthy controls (MMP-9: $p<0.003$, NGAL: $p<0.008$ MMP-9/NGAL: $p<0.01$ ). Significant correlations were observed between MMP-9 and NGAL serum levels and breast disease severity score $(r=0.229, p<0.006$ and $r=0.206, p<0.0$, respectively), whereas a non-significant correlation was found for their complex. MMP-9, NGAL and their complex MMP-9/NGAL levels were not correlated with either Body Mass Index (BMI) or age of patients.

Conclusion: These findings suggest that the serum measurement of MMP-9 and NGAL may be useful in non-invasively monitoring breast cancer progression, while supporting their potential role as early biomarkers of breast disease status.
\end{abstract}




\section{Background}

The lipocalins constitute a family of small-secreted proteins capable of binding hydrophobic molecules. Their principal function is the transport of lipophilic substances but they also participate in immunomodulation and synthesis of prostaglandins [1]. Lipocalin 2 or neutrophil gelatinase-associated lipocalin (NGAL) is a prominent member of the lipocalin family and was originally identified as a glycoprotein in complex with matrix metalloproteinase-9 (MMP-9) in human neutrophils [2,3].

NGAL is an acute phase protein and its expression is upregulated under diverse conditions $[4,5]$. It has been extensively investigated as a biomarker for the early diagnosis of acute kidney injury from diverse etiologies [6-9]. Recent evidence suggests that NGAL expression is induced in many types of human cancer, including breast $[10,11]$, gastric [12], esophageal squamous cell [13], colorectal [5], pancreatic [14,15], lung [16] and ovarian cancer [17]. Regarding breast cancer, Stoesz and coworkers originally reported heterogeneous expression of NGAL mRNA and protein levels in breast cancer tissue that significantly correlated with other markers of poor prognosis including estrogen and progesterone receptor-negative status and high proliferation [10]. Bauer et al recently extended these findings to show that immunohistochemical NGAL expression strongly correlated with negative steroid receptor status, Her-2/neu overexpression, poor histologic grade, the presence of lymph node metastasis and high proliferation index. In univariate analysis, NGAL expression was associated with decreased disease-specific and disease-free survival. In multivariate analysis, NGAL remained an independent prognostic marker for diseasefree survival. These data suggested that tissue NGAL expression could be a valuable prognostic marker in patients with primary breast cancer [11]. Gene expression profiling studies have also confirmed the correlation between NGAL expression and negative estrogen receptor status [18-21].

It has been established that NGAL forms a complex with matrix metalloproteinase-9, thereby preventing MMP-9 autodegradation and increasing its activity in vitro [22]. MMP-9 plays a critical role in cancer progression, invasion and metastasis in several neoplastic diseases including breast cancer [23]. Since MMP-9 is implicated in both early and late processes of tumor progression through the degradation of the extracellular matrix and basement membranes [24], the question whether NGAL and MMP9/NGAL complex contributes to tumor progression was raised.

Fernandez et al investigated the role of MMP-9/NGAL complex in breast tumor growth and its presence in the urine of breast cancer patients [25]. Their findings sug- gested that detection of urinary MMP-9/NGAL complex might represent an independent predictor of disease status. Recently, Smith and coworkers reported significant elevations in MMP-9 and MMP-9/NGAL in brain tumor patients. Their expression correlated with the presence of disease and the response to therapy and could be detected both in tumor tissue and urine samples [26]. An association between MMP-9/NGAL complex and gastric cancer has also been suggested since complex expression in tumor tissue of gastric cancer patients was highly associated with worse survival and was related to the histological and genetic typing of gastric cancer [12]. Moreover, recent studies have suggested an association between MMP-9/NGAL complex expression and abdominal aortic aneurysms as well as osteoarthitis $[27,28]$.

To date, most studies have focused on NGAL and MMP-9/ NGAL tissue expression while only a few have investigated the clinical utility of their urinary measurements. NGAL and MMP-9 are stored in specific granules in neutrophils, while MMP-9 is also found in gelatinase granules. They both mainly exist in forms not associated with each other. Due to its large size, it seems unlikely that the MMP-9/ NGAL complex can be directly filtered from serum to urine. It has thus been suggested that MMP-9 and NGAL are mainly secreted in blood by neutrophils infiltrating the tumor, and are separately excreted in urine where they subsequently form complexes [22]. Although the detection of NGAL and its complex with MMP-9 in systemic circulation seems reasonable, no studies of NGAL and MMP9/NGAL in sera are currently available with the exception of two recent publications on coronary artery disease and polycystic ovary syndrome $[29,30]$. The aim of our study is to evaluate the serum levels of MMP-9, NGAL and MMP-9/NGAL complex in patients with breast abnormalities and investigate their correlation with breast disease severity.

\section{Methods}

The study included 113 women; 35 with sclerosing adenosis, 18 with atypical ductal hyperplasia (ADH), 32 with ductal carcinoma in situ (DCIS), and 28 with invasive breast cancer (IDC), while 30 healthy women served as controls. The mean age of the patients and controls was $52.8 \pm 9.7$ and $55.0 \pm 13.7$ years, respectively, whereas their Body Mass Index (BMI) was $26.2 \pm 4.7$ and $25.9 \pm 4.4$ $\mathrm{kg} / \mathrm{m}^{2}$, respectively. Prior to their enrollment, all the participants were evaluated for the absence of metabolic disorders including diabetes, diagnosed inflammatory disease and abnormal liver and kidney function. Healthy controls were confirmed after clinical examination, mammography and serological analysis during their annual breast screening. Peripheral blood samples were obtained from patients before preoperative histological diagnosis of non-palpable lesions by vacuum-assisted breast biopsy 
(VABB), after overnight fasting. The histopathological data were reported during the statistical analysis, after the blind completion of the assays. Based on the published relative risk of breast benign diseases for cancer, the women were classified into five groups of increasing severity as follows: Healthy controls = Disease Severity Score 1; Sclerosing Adenosis = Disease Severity Score 2; Atypical Ductal Hyperplasia $=$ Disease Severity Score 3; Ductal Carcinoma In Situ $=$ Disease Severity Score 4 and Invasive Breast Cancer = Disease Severity Score 5. The participants were recruited from the Breast Unit, First Department of Propaedeutic Surgery, Athens University Medical School at Hippokratio Hospital between September 2005 and June 2007. The protocol was approved from the Institutional Research Committee and written informed consent was obtained from each patient prior to study entry.

\section{Sample Collection and Assays}

Peripheral venous blood samples were collected between 12:00 a.m. and 14:00 p.m. into separator vacutainers and allowed to clot for 20 to $30 \mathrm{~min}$ at room temperature. The samples were centrifuged at $3000 \times \mathrm{g}$ for $15 \mathrm{~min}$ at $8^{\circ} \mathrm{C}$, divided into aliquots and stored at $-80^{\circ} \mathrm{C}$ until being assayed. The determination of serum MMP-9 concentrations was performed in duplicates, on the Luminex-100 IS (Integrated System) Luminex Corporation, Austin, TX, US using the MMP-9 assay kit manufactured by R\&D Systems, Minneapolis, MN, US. Multianalyte profiling calibration microspheres for classification and reporter readings, as well as sheath fluid were purchased from Luminex Corporation. The acquired fluorescence data were analyzed with the Luminex 2.3 Version software. All analyses were performed according to the manufacturers' protocols. Serum NGAL and MMP-9/NGAL levels were determined in duplicate by solid phase ELISA techniques (R\&D Systems, Minneapolis, MN, US). According to manufacturers, the intra-assay and inter-assay CVs for NGAL range between 3.1 and $4.1 \%$ and 5.6 and $7.9 \%$, respectively, and for MMP-9/NGAL range between 2.3 and $4.1 \%$ and 5.1 and $7.6 \%$, respectively.

\section{Statistical Analysis}

Data are expressed as mean \pm SD. Comparison of analytes within groups was performed using the Student t-test. The correlation coefficient $r$ between the parameters tested was computed using least squares regression analysis. The $p$ values reported are two tailed. All the statistical procedures were performed using the STATGRAFICS 5.1 for Windows program (Graphic Software System, STATPOINT TECHNOLOGIES, INC. Warrenton, Virginia, US).

\section{Results}

Benign breast diseases, encompassing atypical ductal hyperplasia and sclerosing adenosis, have been associated with varying relative risk for developing cancer for patients with no family history, depending on their histological features [31]. Based on these data, we classified our patients into five groups of increasing disease severity and we evaluated the correlation between the expression of MMP-9, NGAL, and MMP-9/NGAL complex and severity score. Mean serum levels of MMP-9, NGAL and MMP-9/ NGAL complex in healthy women and patients with sclerosing adenosis, ADH, DCIS and IDC are presented in Table 1. Patients with invasive carcinoma exhibited significantly increased levels of all three molecules compared to healthy controls (MMP-9: $\mathrm{p}<0.003$, NGAL: $\mathrm{p}<0.008$ MMP-9/NGAL: $\mathrm{p}<0.01)$.

Increased MMP-9 serum levels were observed for all patients compared to healthy subjects (Figure 1). It is noteworthy that women with sclerosing adenosis exhibited significantly elevated MMP-9 expression, similar to that observed for invasive carcinoma (Table 1). A significant positive correlation was observed between MMP-9 serum levels and disease severity score $(\mathrm{r}=0.229$, $\mathrm{p}<$ 0.006). Regarding NGAL, increased serum expression was observed for patients with breast disease compared to healthy controls (Figure 2). NGAL serum levels were similar between women with DCIS, ADH and sclerosing adenosis whereas a marked increase was observed for women with invasive carcinoma (Table 1). A significant positive correlation between NGAL serum levels and disease severity score was found $(r=0.206, p<0.02)$. Higher serum levels of MMP-9/NGAL were observed in IDC, DCIS, ADH and sclerosing adenosis patients compared to healthy women (Figure 3). Increased expression was mainly observed for patients with invasive carcinoma, whereas DCIS, ADH and sclerosing adenosis patients exhibited

Table I: Serum levels of MMP-9, NGAL and MMP-9/NGAL complex.

\begin{tabular}{lccccc}
\hline & $\begin{array}{c}\text { Healthy Controls } \\
\mathbf{( N = 3 0 )}\end{array}$ & $\begin{array}{c}\text { Sclerosing Adenosis } \\
\mathbf{( N = 3 5 )}\end{array}$ & $\begin{array}{c}\text { ADH } \\
(\mathbf{N}=18)\end{array}$ & $\begin{array}{c}\text { DCIS } \\
(\mathbf{N}=\mathbf{3 2})\end{array}$ & $\begin{array}{c}\text { IDC } \\
(\mathbf{N}=\mathbf{2 8})\end{array}$ \\
\hline NGAL (ng/ml) & $70.7 \pm 17.4$ & $78.3 \pm 28.8$ & $79.1 \pm 30.6$ & $80.0 \pm 22.5$ & $87.4 \pm 28.1 *$ \\
MMP-9 (ng/ml) & $264.2 \pm 128.3$ & $402.0 \pm 284.8$ & $326.0 \pm 171.8$ & $330.7 \pm 165.7$ & $392.6 \pm 181.7 * *$ \\
MMP-9/NGAL $(\mathbf{n g} / \mathbf{m l})$ & $39.9 \pm 20.9$ & $54.9 \pm 41.0$ & $53.9 \pm 36.7$ & $49.5 \pm 34.1$ & $60.7 \pm 42.3 * * *$ \\
\hline
\end{tabular}

Serum levels of NGAL, MMP-9 and MMP-9/NGAL complex in healthy controls and patients with Sclerosing adenosis, Atypical ductal hyperplasia $(A D H)$, Ductal carcinoma in situ (DCIS) and Invasive ductal carcinoma (IDC). Data are expressed as mean \pm SD. Significantly increased expression is observed for patients with IDC compared to healthy controls (*NGAL: $p<0.008$, **MMP-9: $p<0.003$, ***MMP-9/NGAL: $p<0.01$ ). 


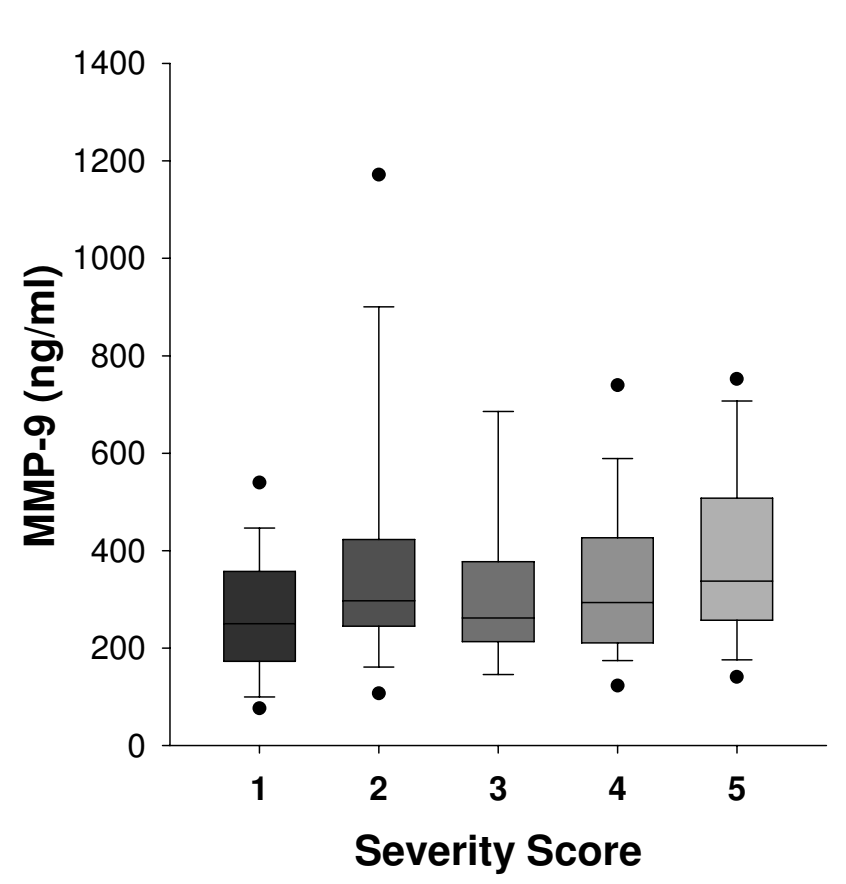

Figure I

Serum levels of MMP-9 depicted as box-plots. (Boxes represent the interquartile range; lines inside boxes represent the median value; whiskers represent $5^{\text {th }}$ and $95^{\text {th }}$ percentiles). The I-5 scale represents breast abnormalities of increasing severity as follows: I: Healthy controls $(\mathrm{N}=30)$, 2: Sclerosing adenosis $(N=35), 3$ : Atypical ductal hyperplasia $(\mathrm{ADH})(\mathrm{N}=18), 4$ : Ductal carcinoma in situ (DCIS) $(\mathrm{N}=32)$ and 5: Invasive ductal carcinoma (IDC) $(\mathrm{N}=28)$.

similar expression levels (Table 1). A positive non-significant correlation was found between MMP-9/NGAL complex expression and disease severity score $(\mathrm{r}=0.123, \mathrm{p}>$ 0.14). MMP-9, NGAL and MMP-9/NGAL complex serum levels were not significantly correlated with either age or BMI of patients $(\mathrm{p}>0.1)$.

\section{Discussion}

NGAL appears to protect MMP-9 from autodegradation, increasing its activity by binding and forming MMP-9/ NGAL complexes. Tumor cells excrete elevated levels of NGAL resulting in an increase in local concentration of MMP-9, which can affect various aspects of tumor progression [22]. NGAL is abundantly expressed in adipose tissue and liver and recent studies have correlated circulating NGAL levels with obesity and its metabolic complications [32,33]. NGAL has also been suggested as a marker of acute kidney injury [6-9]. Therefore normal liver and renal function was clinically confirmed for all patients included in this study prior to their enrollment. Moreover, no patients with metabolic syndromes participated in the

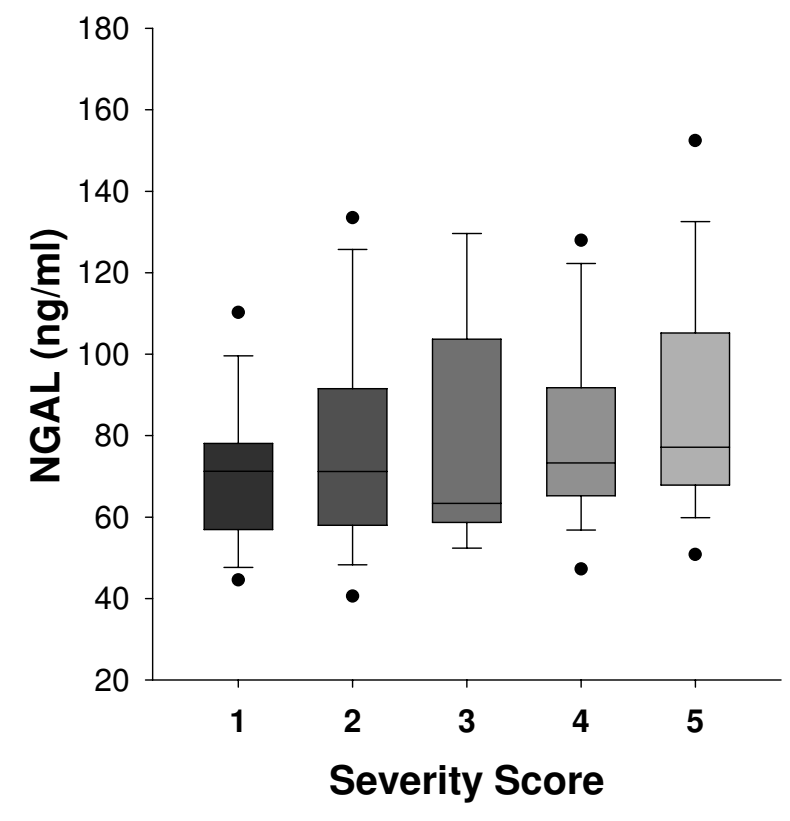

Figure 2

Serum levels of NGAL depicted as box-plots. (Boxes represent the interquartile range; lines inside boxes represent the median value; whiskers represent $5^{\text {th }}$ and $95^{\text {th }}$ percentiles). The I-5 scale represents breast abnormalities of increasing severity as follows: I: Healthy controls $(\mathrm{N}=30)$, 2: Sclerosing adenosis $(N=35), 3$ : Atypical ductal hyperplasia $(\mathrm{ADH})(\mathrm{N}=18), 4$ : Ductal carcinoma in situ (DCIS) $(\mathrm{N}=32)$ and 5: Invasive ductal carcinoma (IDC) $(\mathrm{N}=28)$.

study. According to our findings, serum levels of MMP-9, NGAL, and MMP-9/NGAL were not associated with obesity since no correlation with patients' BMI was observed.

Immunohistochemical studies on breast tissue have associated MMP-9 expression with a higher rate of distant metastases [34-36]. The prevention of the metastatic process is the main aim of the clinicians. Soluble biomarkers could be useful tools in the prediction of patient outcome and management of the disease. Therefore, MMP-9 detection in sera could provide significant information of the tumor biological features. Somiari and coworkers have suggested that circulating MMP-2 and MMP-9 levels are associated with disease severity and may permit the classification of patients with breast disease [24,37]. These findings were recently extended from $\mathrm{Wu}$ et al, who reported that serum MMP-9 levels were significantly elevated in patients with breast cancer compared to those with benign breast disease and healthy controls. Additionally, increased MMP-9 levels were associated with lymph node metastasis, higher tumor stage, lower relapse-free and overall survival [36]. In agreement with these observations, our study reported an increase in MMP-9 expression 


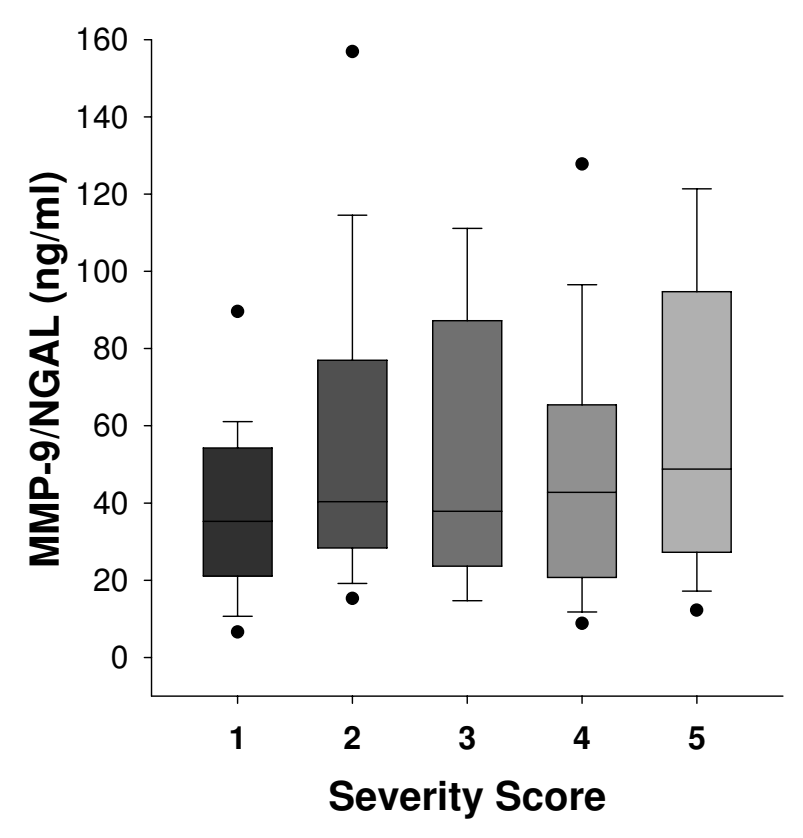

Figure 3

Serum levels of MMP-9/NGAL complex depicted as box-plots. (Boxes represent the interquartile range; lines inside boxes represent the median value; whiskers represent $5^{\text {th }}$ and $95^{\text {th }}$ percentiles). The I-5 scale represents breast abnormalities of increasing severity as follows: I: Healthy controls $(N=30), 2$ : Sclerosing adenosis $(N=35)$, 3: Atypical ductal hyperplasia $(A D H)(N=18), 4$ : Ductal carcinoma in situ (DCIS) $(\mathrm{N}=32)$ and 5: Invasive ductal carcinoma (IDC) $(\mathrm{N}=28)$.

in patients with ADH, DCIS and IDC ( $\mathrm{p}<0.003)$ compared to healthy controls. Our results also document a positive correlation between MMP-9 serum levels and the severity score of breast disease $(\mathrm{p}<0.006)$.

Recent evidence suggests that NGAL expression is associated with cancer invasive progression. Gene expression profiling and analysis of human pancreatic adenocarcinomas by cDNA microarrays, quantitative real-time RT-PCR and immunohistochemistry demonstrated increased expression of NGAL in malignant pancreatic tissue compared to normal [38]. Lim et al reported that tissue expression of NGAL in ovarian tumors changes with disease grade and this is also reflected in serum levels [17]. More specifically, tissue NGAL expression was undetectable in normal ovaries, weak to moderate in benign tissues, while it displayed highest levels in borderline and low-grade tumors. The authors also reported similar findings for NGAL expression in serum, with levels being significantly higher in patients with benign and grade 1 tumors compared to healthy controls. The role of NGAL was also investigated in esophageal squamous cell carcinoma
(ESCC) and it was reported that its tissue expression was significantly higher in ESCC than in normal mucosa, and was positively correlated with cell differentiation [13]. Based on their findings that NGAL in human tissue and urine samples were consistently associated with invasive breast cancer, Yang et al suggested that NGAL may be a potential noninvasive biomarker of breast disease [39]. Our findings further support the hypothesis that NGAL is associated with cancer disease severity. Serum NGAL levels were higher in patients with IDC $(\mathrm{p}<0.008)$ while moderate in patients with DCIS, ADH and sclerosing adenosis compared to healthy controls. A significant positive correlation between NGAL expression and breast disease severity score was also observed $(\mathrm{p}<0.02)$.

Regarding MMP-9/NGAL, current evidence suggests that urinary detection of the complex may represent a new biomarker for the prediction of cancer disease $[25,26]$. NGAL overexpression in human breast cancer cell lines was accompanied by increased tumor growth, MMP-9 activity, angiogenesis and cell proliferation. Moreover, MMP-9/NGAL enzymatic activity was observed in the urine of breast cancer patients but not in healthy controls [25]. Evaluation of MMP-9 and MMP-9/NGAL complex in urine of patients with brain tumors revealed significantly higher expression levels compared to controls, which was also confirmed in tumor tissue. After tumor resection, clearing of biomarkers was observed. The findings support an association between MMP-9 and MMP-9/NGAL urine levels with the presence of disease and response to therapy [26]. In our study, we attempted to evaluate the expression of MMP-9/NGAL complex in serum of patients with breast disease and correlate it with disease severity. Despite observing higher levels of MMP-9/NGAL in IDC ( $\mathrm{p}<0.01)$, DCIS, ADH and sclerosing adenosis patients compared to healthy controls, a positive non-significant correlation between complex expression and disease severity score was found. However, future studies including a higher number of patients could elucidate the significance of serum MMP-9/NGAL expression in patients with breast disease.

The relation between breast benign diseases and invasive cancer has been a matter of discussion for many years, as these lesions are considered precursors in malignant transformation. Sclerosing adenosis is a benign proliferative lesion without atypia with a relative risk for malignant breast disease of 1.3-1.9, while ADH has a slightly higher risk $(\times 3.9-5.0)$ [31]. Since sclerosing adenosis and ADH are believed to constitute distinct precursors of invasive breast carcinoma, we attempted to investigate potential differences in the tested parameters. Higher levels of NGAL and MMP-9/NGAL complex were observed for both groups of patients compared to healthy controls, whereas MMP-9 expression was particularly elevated in 
the sclerosing adenosis group. This observation seems to support the idea that this lesion is a distinct entity of benign disease. Whether serum levels of MMP-9, NGAL and their complex can reflect the relative risk of patients with benign diseases for developing breast cancer remains to be investigated in future studies.

Improved non-operative diagnostic techniques enable the detection of breast cancer at an earlier stage. At the same time, serum measurements represent a non-invasive, easily accessible method for the study of biomarkers as screening tools for risk assessment, diagnosis and prognosis of breast cancer. The present study was designed in an effort to reveal specific biomarkers associated with breast disease progression. Our data suggest that MMP-9 and NGAL are positively correlated with breast disease severity, with a potential clinical utility as early markers of breast disease status.

\section{Conclusion}

In spite of the supporting evidence in the literature, the significance of circulating MMP-9 in prognosis and progression of breast cancer disease requires further clarification. On the other hand, NGAL and MMP-9/NGAL complex have not yet been evaluated in breast cancer. Even though the detection of NGAL and MMP-9/NGAL complex in systemic circulation is likely to directly reflect their tissue expression, scarce data are currently available on the significance of their serum measurement in cancer disease. To our knowledge, this is the first study attempting to investigate the serum expression of MMP-9, NGAL and MMP-9/NGAL complex during diagnostic work-up of patients with breast abnormalities and correlate it with the severity of the disease. Our findings suggest that both MMP-9 and NGAL serum levels are correlated with breast cancer progression since they seem to follow a gradual increase with disease severity, supporting their potential role as early biomarkers.

\section{Competing interests}

The authors declare that they have no competing interests.

\section{Authors' contributions}

XP (Ph.D.) performed the experimental analysis and interpretation of the data and wrote the article. AG (Ph.D.) was responsible for the conception and design of the study, the revision of the article and its final approval. EK (BSc) performed the experimental analysis and interpretation of the data. FZ (MD) and IF (MD) acquired patients' characteristics and samples. AN (MD) performed the immunohistochemical analysis of the biopsies. IP (Ph.D.) and EG (MD) performed the statistical analysis, data interpretation and edited the article. GZ (MD, FACS) performed the VABB biopsies and edited the article. All authors read and approved the final manuscript.

\section{Acknowledgements}

GRANT/FUNDING SUPPORT: Funding was received from Hellenic Anticancer Institute (to $A G$ ). The funding sources played no role in the study design; in the collection, analysis, and interpretation of data; in the writing of the report; or in the decision to submit the report for publication.

FINANCIAL DISCLOSURES: None declared.

\section{References}

I. Flower DR: The lipocalin family: structure and function. Biochem J 1996, 3 18: I-14.

2. Triebel S, Blaser J, Reinke H, Tschesche H: A 25 kDa alpha 2microglobulin-related protein is a component of the $125 \mathrm{kDa}$ form of human gelatinase. FEBS Lett 1992, 3 | 4:386-8.

3. Kjeldsen L, Johnsen $A H$, Sengelov $H$, Borregaard $N$ : Isolation and primary sequence of NGAL, a novel protein associated with human neutrophil gelatinase. J Biol Chem 1993, 268:10425-32.

4. Xu S, Venge P: Lipocalins as biochemical markers of disease. Biochim Biophys Acta 2000, I 482:298-307.

5. Nielsen BS, Borregaard N, Bundgaard JR, Timshel S, Sehested M, Kjeldsen L: Induction of NGAL synthesis in epithelial cells of human colorectal neoplasia and inflammatory bowel diseases. Gut 1996, 38:4|4-20.

6. Mori L, Lee HT, Rapoport D, Drexler IR, Foster K, Yang J, SchmidtOtt KM, Chen X, Li JY, Weiss S, Mishra J, Cheema FH, Markowitz G, Suganami T, Sawai K, Mukoyama M, Kunis C, D'Agati V, Devarajan P, Barasch J: Endocytic delivery of lipocalin-siderophore-iron complex rescues the kidney from ischemia-reperfusion injury. J Clin Invest 2005, I I 5:6 10-21.

7. Mishra J, Dent C, Tarabishi R, Mitsnefes MM, Ma Q, Kelly C, Ruff SM, Zahedi K, Shao M, Bean J, Mori K, Barasch J, Devarajan P: Neutrophil gelatinase-associated lipocalin (NGAL) as a biomarker for acute renal injury after cardiac surgery. Lancet 2005 , 365: $123 \mid-8$.

8. Wagener G, Jan M, Kim M, Mori K, Barasch JM, Sladen RN, Lee HAT: Association between increases in urinary neutrophil gelatinase-associated lipocalin and acute renal dysfunction after adult cardiac surgery. Anesthesiology 2006, 105:485-9I.

9. Mishra J, Ma Q, Kelly C, Mitsnefes M, Mori K, Barasch J, Devarajan P. Kidney NGAL is a novel early marker of acute injury following transplantation. Pediatr Nephrol 2006, $21: 856-63$.

10. Stoesz SP, Friedl A, Haag JD, Lindstrom MJ, Clark GM, Gould MN: Heterogeneous expression of the lipocalin NGAL in primary breast cancers. Int / Cancer 1998, 79:565-72.

II. Bauer M, Eickhoff JC, Gould MN, Mundhenke C, Maass N, Friedl A: Neutrophil gelatinase-associated lipocalin (NGAL) is a predictor of poor prognosis in human primary breast cancer. Breast Cancer Res Treat 2008, 108:389-97.

12. Kubben FJ, Sier CF, Hawinkelas LJ, Tschesche H, van Duijn W, Zuidwijk K, Reijden J] van der, Hanemaaijer R, Griffioen G, Lamers CB, Verspaget HW: Clinical evidence for a protective role of lipocalin-2 against MMP-9 autodegradation and the impact for gastric cancer. Eur J Cancer 2007, 43: I869-76.

13. Zhang H, Xu L, Xiao D, Xie J, Zeng H, Wang Z, Zhang X, Niu Y, Shen $Z$, Shen J, Wu X, Li E: Upregulation of neutrophil gelatinaseassociated lipocalin in oesophageal squamous cell carcinoma: significant correlation with cell differentiation and tumour invasion. J Clin Pathol 2007, 60:555-6I.

14. Furutani M, Arii S, Mizumoto M, Kato M, Imamura M: Identification of a neutrophil gelatinase-associated lipocalin mRNA in human pancreatic cancers using a modified signal sequence trap method. Cancer Lett 1998, 1 22:209-14.

15. Laurell H, Bouisson M, Berthelemy P, Rochaix $P$, Dejean S, Besse $P$, Susini C, Pradayrol L, Vaysse N, Buscail L: Identification of biomarkers of human pancreatic adenocarcinomas by expression profiling and validation with gene expression analysis in endoscopic ultrasound-guided fine needle aspiration samples. World J Gastroenterol 2006, I 2:3344-5 I.

16. Friedl A, Stoesz SP, Buckley P, Gould MN: Neutrophil gelatinaseassociated lipocalin in normal and neoplastic human tissues. Cell type-specific pattern of expression. Histochem J 1999, 31:433-41.

17. Lim R, Ahmed N, Borregaard N, Riley C, Wafai R, Thompson EW, Quinn MA, Rice GE: Neutrophil gelatinase-associated lipocalin 
(NGAL) an early-screening biomarker for ovarian cancer: NGAL is associated with epidermal growth factor-induced epithelio-mesenchymal transition. Int J Cancer 2007, | 20:2426-34.

18. Gruvberger S, Ringnér M, Chen Y, Panavally S, Saal LH, Borg A, Fernõ $M$, Petrson C, Meltzer PS: Estrogen receptor status in breast cancer is associated with remarkably distinct gene expression patterns. Cancer Res 2001, 6 1:5979-84.

19. Vijver MJ van de, He YD, van't Veer LJ, Dai H, Hart AA, Voskuil DW, Schreiber GJ, Peterse JL, Roberts C, Marton MJ, Parrish M, Atsma D, Witteveen A, Glas A, Delahaye L, Velde T van der, Bertalink $H$, Rodenhuis S, Rutgers ET, Friend SH, Bernards R: A gene-expression signature as a predictor of survival in breast cancer. $\mathrm{N}$ Engl J Med 2002, 347: 1999-2009.

20. van't Veer LJ, Vijver MJ van de, He YDD, Hart AAM, Mao M, Peterse $H L$, Kooy $K$ van der, Marton MJ, Witteveen AT, Schreiber GJ, Kerkhoven RM, Roberts C, Linsley PS, Bernards R, Friend SH: Gene expression profiling predicts clinical outcome of breast cancer. Nature 2002, 415:530-6.

21. Wang Y, Klijn JG, Zhang Y, Sieuwerts AM, Look MP, Yang F, Talantov D, Timmemans M, Meijervan Gelder ME, Yu J, Jatkoe T, Berns EM, Atkins D, Foekens JA: Gene-expression profiles to predict distant metastasis of lymph-node-negative primary breast cancer. Lancet 2005, 365:67I-9.

22. Yan L, Borregaard N, Kjeldsen L, Moses MA: The high molecular weight urinary matrix metalloproteinase (MMP) activity is a complex of gelatinase B/MMP-9 and neutrophil gelatinaseassociated lipocalin (NGAL). Modulation of MMP-9 activity by NGAL. J Biol Chem 200I, 276:37258-65.

23. Turpeenniemi-Hujanen T: Gelatinases (MMP-2 and -9) and their natural inhibitors as prognostic indicators in solid cancers. Biochimie 2005, 3-4:287-97.

24. Somiari SB, Shriver CD, Heckman C, Olsen C, Hu H, Jordan R, Arciero C, Russell S, Garguilo G, Hooke J, Somiari RI: Plasma concentration and activity of matrix metalloproteinase 2 and 9 in patients with breast disease, breast cancer and at risk of developing breast cancer. Cancer Lett 2006, 233:98-107.

25. Fernandez CA, Yan L, Louis G, Yang J, Kutok JL, Moses MA: The matrix metalloproteinase-9/neutrophil gelatinase-associated lipocalin complex plays a role in breast tumor growth and is present in the urine of breast cancer patients. Clin Cancer Res 2005, I I:5390-5.

26. Smith ER, Zurakowski D, Saad A, Scott RM, Moses MA: Urinary biomarkers predict brain tumor presence and response to therapy. Clin Cancer Res 2008, 14:2378-86.

27. Folkesson M, Kazi M, Zhu C, Silveira A, Hemdahl AL, Hamsten A Hedin U, Swedenborg J, Eriksson P: Presence of NGAL/MMP-9 complexes in human abdominal aortic aneurysms. Thromb Haemost 2007, 98:427-33.

28. Gupta K, Shukla M, Cowland JB, Malemud CJ, Haqqi TM: Neutrophil gelatinase-associated lipocalin is expressed in osteoarthritis and forms a complex with matrix metalloproteinase 9. Arthritis Rheum 2007, 56:3326-35

29. Paulsson J, Dadfar E, Held C, Jacobson SH, Lundahl J: Activation of peripheral and in vivo transmigrated neutrophils in patients with stable coronary artery disease. Atherosclerosis 2007, 192:328-34.

30. Diamanti-Kandarakis E, Livadas S, Kandarakis SA, Margeli A, Papassotiriou I: Serum concentrations of atherogenic proteins neutrophil gelatinase-associated lipocalin and its complex with matrix metalloproteinase-9 are significantly lower in women with polycystic ovary syndrome: hint of a protective mechanism? EurJ Endocr 2008, I 58:525-31.

31. Guray M, Sahin AA: Benign breast diseases: Classification, diagnosis, and management. The Oncologist 2006, I I:435-449.

32. Wang Y, Lam KS, Kraegen EW, Sweeney G, Zhang J, Tso AW, Chow WS, Wat NM, Xu JY, Hoo RL, Xu A: Lipocalin-2 is an inflammatory marker closely associated with obesity, insulin resistance, and hyperglycemia in humans. Clin Chem 2007, 53:34-4I.

33. Yan QW, Yang Q, Mody N, Graham TE, Hsu CH, Xu Z, Houstis NE, Kahn BB, Rosen ED: The adipokine lipocalin 2 is regulated by obesity and promotes insulin resistance. Diabetes 2007 , 56:2533-40

34. Vizoso FJ, González LO, Corte MD, Rodríguez JC, Vázquez J, Lamelas ML, Junquera S, Merino AM, García-Muñiz JL: Study of matrix met- alloproteinases and their inhibitors in breast cancer. $\mathrm{Br} J \mathrm{Can}$ cer 2007, 96:903-II.

35. Kim HJ, Park Cl, Park BW, Lee HD, Jung WH: Expression of MT-I MMP, MMP2, MMP9 and TIMP2 mRNAs in ductal carcinoma in situ and invasive ductal carcinoma of the breast. Yonsei Med | 2006, 47:333-42.

36. Wu ZS, Wu Q, Yang JH, Wang HQ, Ding XD, Yang F, Xu XC: Prognostic significance of MMP-9 and TIMP-I serum and tissue expression in breast cancer. Int J Cancer 2008, I 22:2050-6.

37. Somiari SB, Somiari RI, Heckman CM, Olsen CH, Jordan RM, Russell SJ, Shriver CD: Circulating MMP2 and MMP9 in breast cancer -- potential role in classification of patients into low risk, high risk, benign disease and breast cancer categories. Int J Cancer 2006, II 9: I403-II.

38. Laurell H, Bouisson M, Berthelemy P, Rochaix P, Dejean S, Besse P, Susini C, Pradayrol L, Vaysse N, Buscail L: Identification of biomarkers of human pancreatic adenocarcinomas by expression profiling and validation with gene expression analysis in endoscopic ultrasound-guided fine needle aspiration samples. World ] Gastroenterol 2006, I 2:3344-5 I.

39. Yang J, Bielenberg DR, Rodig SJ, Doiron R, Clifton MC, Kung AL, Strong RK, Zurakowski D, Moases MA: Lipocalin 2 promotes breast cancer progression. PNAS 2009, 106:39|3-8.

\section{Pre-publication history}

The pre-publication history for this paper can be accessed here:

http://www.biomedcentral.com/1471-2407/9/390/pre pub

Publish with Biomed Central and every scientist can read your work free of charge

"BioMed Central will be the most significant development for disseminating the results of biomedical research in our lifetime. "

Sir Paul Nurse, Cancer Research UK

Your research papers will be:

- available free of charge to the entire biomedical community

- peer reviewed and published immediately upon acceptance

- cited in PubMed and archived on PubMed Central

- yours - you keep the copyright 